\title{
Research on Improving English Reading Proficiency for Postgraduate Students Based on Interactive Reading Model
}

\author{
Yushuang ZHU \\ College of Foreign Languages, Jianghan University,Wuhan, 430056, China \\ Email: shirley_tony@163.com
}

Key words: English Reading; Proficiency; Postgraduate Students; Interactive Reading Mode

\begin{abstract}
Although there are a lot of researchers who have studied the relationship between reading proficiency and interactive reading model, most of them focus on the undergraduates or English major students. This paper mainly pays close attention to the relationship between reading proficiency and interactive reading model for the postgraduate students. The main aims of the experiment are to test and prove whether the interactive reading model is more effective than the traditional teaching method, and whether the interactive reading model can improve postgraduates reading ability and enhance students' learning motivation.
\end{abstract}

\section{Introduction}

In recent years, with the continuous expansion of graduate education in our country, the society has higher requirement to postgraduates' academic ability. [1]For postgraduate students, learning English is not only just for the reading comprehension on the examination paper and operating skillfully a scientific research software used in English, but also for the sake of reading and searching useful literature abroad successfully. [2]The improvement of English reading ability for postgraduate academic study plays an important role. Researchers regard "Interactive reading model" as one of the most effective methods to develop students' reading efficiency and ability. Schema theory research shows that the most efficient way of reading is speaking from the model and the model of organic combination (Rumelhart, 1989). [3]Therefore the author applies the interactive reading model which is regarded reading as the combination of the former two models, hoping to improve the postgraduate students' reading ability and reading interest. It can at the same time from the concrete to the abstract, low level to high level, it is a dynamic process. The present research aims to study whether the interactive reading model which is applied to teaching reading for post-graduate English classes is more active or not, so as to strengthen post-graduate students' reading ability and make full use of "interactive reading model".

\section{Research Methodology}

Research questions

The purpose of this thesis is to prove that classroom education is still necessary for postgraduate students. So the experiment is done to research the following questions:

1) In an interactive reading class, which means is better in promoting the interaction between teachers and students?

2) Can interactive reading teaching model improve the graduate students' English reading ability? If yes, what's the mainly respect?

Subjects

The subjects are 86 graduate students from two classes in their first year of postgraduates in Jianghan University. Class 1 is experimental class (EC) and the control class (Class 2). Inside the control class, the teacher used the traditional reading teaching method.

Questionnaire

The questionnaire consisted of two parts. Before the experiment, the first questionnaire is to 
know about the students' previous learning interests, the attitudes to English reading learning and the present situation of EFL reading class. [4] It is based upon that of Zhou Xing \& Zhou Yun (2002) which is about classroom activities and interaction-based pattern. The author has made some modification. Questionnaire 2 is designed mainly to know about the difference of the students' attitude towards reading by learning the interactive reading model before and after the experiment. Data collection and analysis

After the questionnaire for the last time, all statics or the collected data I need to have the collected data, the author sorts through the data and the interview to collect. To analyze the data by SPSS17.0.

\section{Result and discussion}

Analysis and discussion of pre-test

In order to conform that students both in experimental class (EC) and in the controlled class (CC) have the similar reading comprehension ability, a comprehension reading test is conducted before the experiment for the two classes. The reading comprehension test is chosen from CET-6, which contains 4 passages, 5 questions in each passage, one mark for each question, so the full mark for each test are 20 scores. With the help of SPSS, the following "Independent-Samples T-test" table is to prove the two classes have the similar scores before using the interactive reading model.

Table 1 Independent-Samples T-test for the pre-test Group Statistics

\begin{tabular}{|cc|c|c|c|c|}
\hline & Group & N & Mean & Std.Deviation & Std. Error Mean \\
\hline CC1 & 1 & 42 & 21.8571 & 5.66363 & .87392 \\
EC1 & 2 & 44 & 22.8636 & 6.53289 & .98487 \\
\hline
\end{tabular}

According to Table 1 descriptive statistics show that the experimental class (EC) (mean=21.8571, Std. deviation=5.66363) and the control class (CC) (mean=22.8636, Std. deviation=6.53289) do not have obvious difference. That is to say the reading ability of both classes is nearly the same.

Table 2 Independent-Samples Test

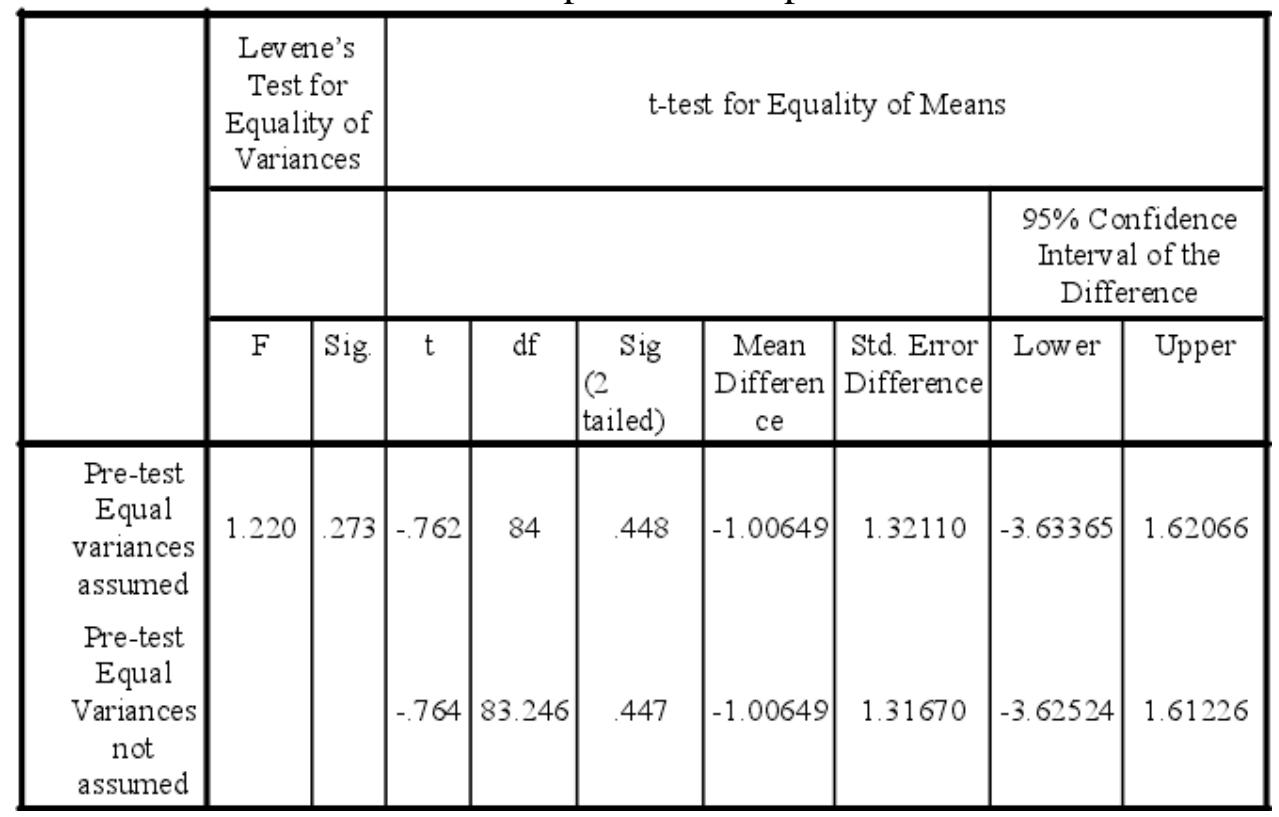

The descriptive statistics in Table 2is the independent samples test for the two classes (CC\&EC), which is designed to ensure the primary reading capacity of them are almost the same. Based on the Levine's test for equality of variances, the significance is 0.273 which is higher than 0.05 and it means the variances assumed are equal. 
The tables above are the descriptive statistics for pre-test on the experimental class (EC) and the control class (CC). There are altogether 86 students in two classes who are taught by the same teacher. So the value of Sig. (2-tailed) is 0.448 , which is higher than 0.05 . The $95 \%$ Confidence Interval of the Difference, the range of lower and the upper contains zero. All the data mean that there is no clear difference between the controlled class and the experimental class. That is to say, two classes have a parallel level in reading comprehension ability.

discussion of post-test

Table 3 Independent-Samples T-test for the post-test Group Statistics

\begin{tabular}{|ll|c|c|c|c|}
\hline \multicolumn{1}{|c|}{ Group } & $\mathrm{N}$ & Mean & Std.Deviation & Std. Error Mean \\
\hline $\mathrm{CC} 2{ }_{1}$ & 42 & 23.7619 & 5.07894 & .78370 \\
$\mathrm{EC} 2$ & 2 & 44 & 29.0455 & 5.56549 & .83903 \\
\hline
\end{tabular}

Table 3 shows that the mean of the controlled class is 23.7619.

Table 4 Independent-Samples Test

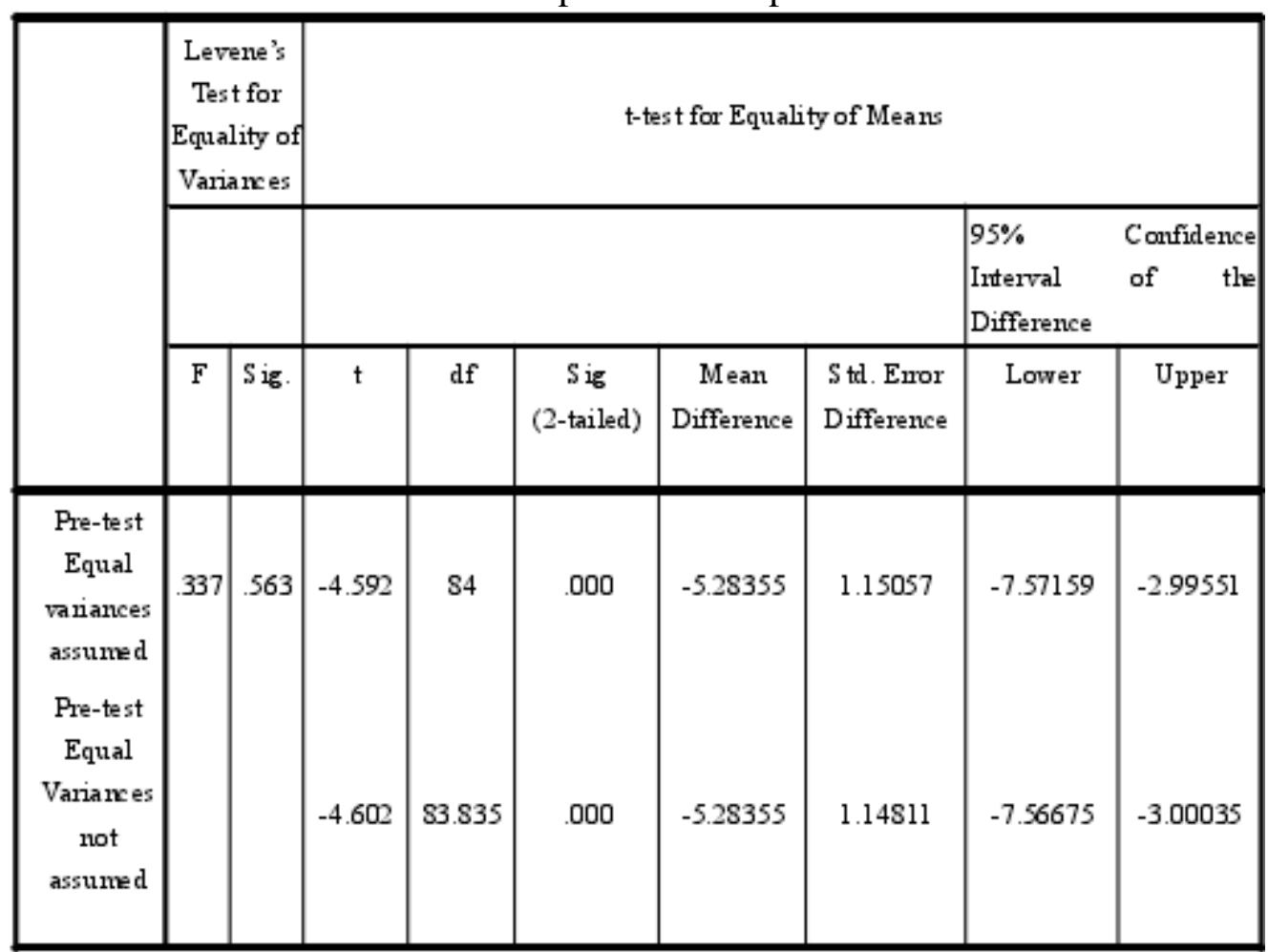

According to the Table 4 the students' scores about the reading comprehension have changed. From the Table 4, the significance is 0.563 which is higher than 0.05 . Therefore, the value of Sig. (2-tailed) is 0.000 , and the variances assumed which is lower than 0.05 . What's more, based on the 95\% Confidence Interval of the Difference, the range of lower and the upper doesn't contain zero. Thus these descriptive statistics from the tables can clearly explain that there is an obvious difference between the two classes and the scores of experimental class are better and higher than that of the controlled class.

Discussion of pre-test and post-test 
Table 5 Paired-Samples Statistics

\begin{tabular}{|c|c|c|c|c|c|}
\hline Group & Mean & N & Std. Deviation & Std. Error Mean & \\
\hline CC1 & 21.8571 & 42 & 5.6636 & .87392 & \\
CC2 & 23.8571 & 42 & 5.0441 & .77831 & \\
EC1 & 22.9091 & 44 & 6.4909 & .97853 & \\
EC2 & 29.0455 & 44 & 5.5655 & .83903 & \\
\hline
\end{tabular}

Table 6 Paired Samples Correlations

\begin{tabular}{|c|c|c|c|c|}
\hline & Pair & $\mathrm{N}$ & Correlation & Sig. \\
\hline Pair1 & $\mathrm{CC} 1 \& \mathrm{CC} 2$ & 42 & .983 & .000 \\
\hline Pair2 & $\mathrm{EC} 1 \& \mathrm{EC} 2$ & 44 & .941 & .000 \\
\hline
\end{tabular}

Table 7 Paired samples t-test

\begin{tabular}{|c|c|c|c|c|c|c|c|c|}
\hline & \multicolumn{5}{|c|}{ Paired Diffe rences } & \multirow{3}{*}{$t$} & \multirow{3}{*}{$\mathrm{df}$} & \multirow{3}{*}{$\begin{array}{c}\text { Sig. } \\
\text { (2-tailed) }\end{array}$} \\
\hline & \multirow[b]{2}{*}{ Mean } & \multirow[b]{2}{*}{$\begin{array}{c}\text { Std } \\
\text { Deviation }\end{array}$} & \multirow[b]{2}{*}{$\begin{array}{l}\text { Std. Enor } \\
\text { Difference }\end{array}$} & \multicolumn{2}{|c|}{$\begin{array}{l}95 \% \text { Confidence } \\
\text { Interval of the } \\
\text { Difference }\end{array}$} & & & \\
\hline & & & & Lower & Upper & & & \\
\hline Pair $1 \mathrm{CC} 1-\mathrm{CC} 2$ & -2.000 & 1.169 & .1803 & -2.364 & -1.636 & -11.091 & 41 & .000 \\
\hline Pair 2 EC1 - EC2 & -6.136 & 2.258 & .3404 & -6.823 & -5.450 & -18.029 & 43 & .000 \\
\hline
\end{tabular}

According to the table 5, table 6 and table7, the 95\% Confidence Interval of The Difference in both the Pair 1 and pair2, the ranges of lower and the upper don't contain zero. The values of Sig. (2-tailed) are 0.000 , which are lower than 0.05 . The mean score of CC1 is 21.8571 while the mean score of CC2 is 23.8571. On the other hand, the mean score of EC1 is 22.9091; however the mean score of EC2 is 29.0455. These data can indicate that both classes have a clear change in English reading scores and the scores of the classes increase clearly from the pre-test to the post-test.

\section{Conclusion}

In this paper, the researcher does the independent-sample t-test, paired-sample t-test, an experimental study about postgraduates' English teaching and gets the findings from students' questionnaire and correlation analysis of reading comprehension scores of both experimental class and control class by means of SPSS statistical software. [5] Research results show that interactive reading model and the corresponding reading skills and strategies make a great contribution to developing post-graduated students' reading ability. The limitation of this study is that the number of the subjects is only eighty-six, which means that the sample size is very small. Therefore, it might influence the results of the research. 


\section{References}

[1]. Mori, S. Redefining Motivation to Read in a Foreign Language. Reading in Foreign Language. New York: Longman. 2002.

[2] Grabe. Current Developments in Second Language Reading Research. ESOL Quarty, 1991.3(25):375-406.

[3] Hall, L. A. Teachers and Content Area Reading: attitudes, beliefs and change. Teaching and Teacher Education, 2011. (21): 403-414.

[4] Anderson, Neil. Exploring Second Language Reading: Issues and the Strategies. Beijing: Foreign Language Teaching and Research Press. 1999.

[5] Scovel T.The effect of affect on foreign language learning: a review of the anxiety research. Language Learning Journal. 1978 